\title{
Experiences from a New Project-Driven and Outcome- Based Educational Concept in a Blasting Engineering Study Program
}

\author{
https://doi.org/10.3991/ijet.v16i08.21371 \\ Zhiqiang Yin, Zenghui Liu \\ Anhui University of Science and Technology, Huainan, China \\ Zhixiong Zhang $\left.{ }^{(}\right)$ \\ Beibu Gulf University, Qinzhou, China \\ zzxiong@bbgu. edu. cn \\ Jucai Chang, Xuelong Hu \\ Key Laboratory of Safety and High-efficiency Coal Mining, Huainan, China
}

\begin{abstract}
Blasting engineering is a very comprehensive and practical curriculum. However, the traditional method of teaching this curriculum is relatively simple and emphasizes theory teaching over practice teaching, the introduction of classical methods over the expansion of new methods, and the training of individual abilities over the cultivation of team spirit. To address these problems, a new project-driven teaching method based on the concept of outcomesbased education (OBE) certified by the engineering education specialty was explored in this study. The teaching goals were determined based on the index points of the graduation requirements for mining engineering majors. The teaching process was divided into four stages, namely, project investigation and analysis, project parameter design, project report evaluation, and project display and feedback. The special subject on the deep-hole bench blasting scheme of an open-pit mine was taken as an example to explore the related work that needs to be completed by students in different phases and the related abilities and qualities that need cultivation. Lastly, the limitations in the ability training of students in the teaching process were continuously improved through an evaluation and feedback of teaching quality. Results of a four-year teaching practice show that the OBE-based project-driven teaching method not only effectively overcomes the drawbacks of the traditional teaching method but also effectively improves the comprehensive abilities and qualities of students.
\end{abstract}

Keywords - Blasting engineering, project-driven method, teaching reform, practical teaching, OBE 


\section{Introduction}

Blasting engineering is a key professional technical curriculum for mining and transportation engineering. A very comprehensive and practical curriculum, blasting engineering is a core program that aims to cultivate the fundamental abilities of blast engineers taking professional posts in the mining and civil engineering industries, such as design, construction, and management. The traditional engineering education in China focuses on theory teaching supplemented by practical teaching. By contrast, engineering education in European colleges focuses more on curriculum setting and imparting knowledge in the classroom. Specifically, the latter focuses on cultivating talent and strengthening the personal professional skills and specialty-related working competencies of students. In addition, real and complete engineering project implementation becomes difficult in the traditional teaching process given that blasting engineering involves high risks, costs, and energy consumption. Therefore, blasting engineering curriculums in colleges of different universities are being taught via a separate implementation of theory teaching and practical operation, which challenges students in understanding the teaching contents, thereby resulting in a teaching effect that is far from ideal. For instance, these students have no idea how to start designing a blasting scheme. The main problems of this teaching process are summarized as follows:

1. The classroom teaching pattern mainly focuses on the one-way instillation of teachers. When teaching blasting engineering, teachers merely teach the curriculum, whereas the students mechanically listen and demonstrate poor subjective learning initiatives. Moreover, these students feel bored easily when studying blasting engineering principles, thereby generating a teaching effect that is far from ideal. Furthermore, blasting engineering teaching involves an abundant number of knowledge points, thereby challenging students in understanding the associations among these knowledge points and in forming a systematic knowledge network.

2. The teaching assessment method mainly combines test papers with regular performance evaluations. Test papers are principally based on theoretical knowledge contained in textbooks, whereas regular performance evaluations mainly consider attendance, assignments, and class participation. This assessment mode aggravates the dependence of students on textbooks and subsequently prevents teachers from assessing how capable their students can apply what they have learned in actual engineering practice and improve their adaptability to the post of blasting engineers, which will subsequently affect their future career.

Faced with the future demand for blasting engineering professionals, how to improve the comprehensive practical abilities of students while imparting fundamental theoretical knowledge related to blasting has become an important direction for the blasting engineering curriculum teaching reform [1-2]. Outcomes-based education (OBE) is a core concept that has passed the professional certification of engineering education [3]. Unlike the traditional "teaching content-oriented" concept, OBE is "student centered," formulates the teaching objects, implements the teaching process, 
and evaluates teaching quality in a student-learning-outcomes-oriented manner; by focusing on cultivating the abilities of students and improving their qualities, OBE can continuously enhance teaching quality through a continuous improvement of their students [4-5]. This project-driven method converts the knowledge points in the traditional engineering discipline into several teaching projects and organizes and carries out teaching work based on teaching projects in order for their students to directly participate in these projects and to complete the teaching process [6-7]. The main feature of the project-driven method is that curriculum teaching always focuses on teaching projects, particularly on cultivating the practical abilities, innovation, and ability of students to independently acquire information and autonomously establish knowledge. Based on OBE, the project-driven method was applied to the curriculum teaching of blasting engineering, and the concrete implementation methods were expounded by combining related cases.

\section{State of Art}

Educators have conducted many studies to cultivate the practical abilities of their students and to help them comprehensively utilize their learned knowledge. Liu Q et al. [8] explored the aspects of a curriculum system (e.g., teaching methods) and reconstructed theory learning, curriculum experiment, and curricular practical training in the "blasting engineering" curriculum from three aspects, namely, teaching content, teaching means, and assessment method, with the goal of improving the practical abilities of their students. By virtual simulation, multimedia, man-computer interaction, database, and network communication, Zhang F. et al. [9] constructed a teaching platform for virtual simulation experiments on blasting safety in roadway excavation. Zhang H. et al. [10] reformed this curriculum from the perspectives of teaching method, information-based teaching means, diversified teaching resources, and projectbased teaching management. However, these reform measures all aim at teachers and curriculum construction. Despite highlighting the functions of teachers, this pattern highlights theory while neglecting practice and lacks feedback and improvement of the learning conditions of students. Therefore, this pattern is unable to cultivate the post capabilities of students and ignores the actual needs in curriculum teaching along with the lack of its characteristics.

The project-driven teaching method, which is based on the working process, integrates practical enterprise projects into the blasting engineering curriculum. Driven by their tasks, students can rapidly master basic curriculum theories and realize an organic theory-practice integration. Some scholars have also probed into the project-driven teaching method. For instance, Zhylkybay [11] expounded on the phases and implementation process of the project-driven method. By taking an undergraduate thesis project as an example, Agudamu [12] demonstrated the effectiveness of the projectdriven teaching method in improving the comprehensive knowledge and practical abilities of students. Qian C. Y. [13] pointed out that by focusing on students, the project-driven teaching method can give full play to their creative potential and improve their practical abilities. He also called for future studies to examine how the 
individual incentive function of team assessment can be applied. Given that assessment and feedback are fully carried out after project teaching, addressing the problems in project implementation and improving the comprehensive knowledge mastery of students should be further examined.

As an advanced educational concept, OBE has formed a complete set of theoretical systems and implementation models after several decades of theoretical and practical exploration [3]. In an OBE-based engineering education and teaching reform, Tsinghua University has shifted from a teacher-centered to a student-centered curriculum and from quality monitoring to continuous improvement [14]. Liu Q. improved and optimized the teaching scheme for a software engineering curriculum based on OBE and, driven by the learning outcomes, highlighted the cultivation of students' technical skills, engineering practice abilities, and ability to solve complicated problems [15]. Previous research on teaching shows that, to improve teaching mode based on OBE, cultivating the abilities of students in solving complicated engineering problems should be taken as the final goal in the overall teaching design, and their weaknesses in ability cultivation should be continuously adjusted and improved in the teaching practice [16-17].

Therefore, the blasting engineering curriculum reform was explored through the OBE-based project-driven teaching method. The engineering-projects-reshaped concrete implementation process of curriculum contents was expounded from four aspects, namely, project investigations and analysis, project parameter design, project report compilation, and project display and feedback, in curriculum teaching.

\section{Project-Driven Teaching Model of the Blasting Engineering Curriculum Based on OBE}

\subsection{Curriculum objective design based on OBE}

The engineering education teaching model based on OBE can efficiently address problems in traditional teaching. This model designs, implements, and evaluates teaching by focusing on its objectives. Compared with the traditional teaching model, this teaching mode focuses on the learning outcomes, practice, and students. This model is illustrated in Fig. 1. As shown in this figure, this teaching model formulates the training objectives based on the social needs and industrial development of an undergraduate program. The graduation requirements are reasonably designed through the training objectives and are completely supported by the curriculum system via index points. Each curriculum in the curriculum system is used to design the curriculum objectives according to the index points of graduation requirements it supports. Therefore, the curriculum teaching program, teaching method, and assessment plan are all designed based on the curriculum objectives, and feedback is obtained by using the achievement evaluation mechanism to enhance teaching quality and realize a continuous improvement of the teaching program [18]. 


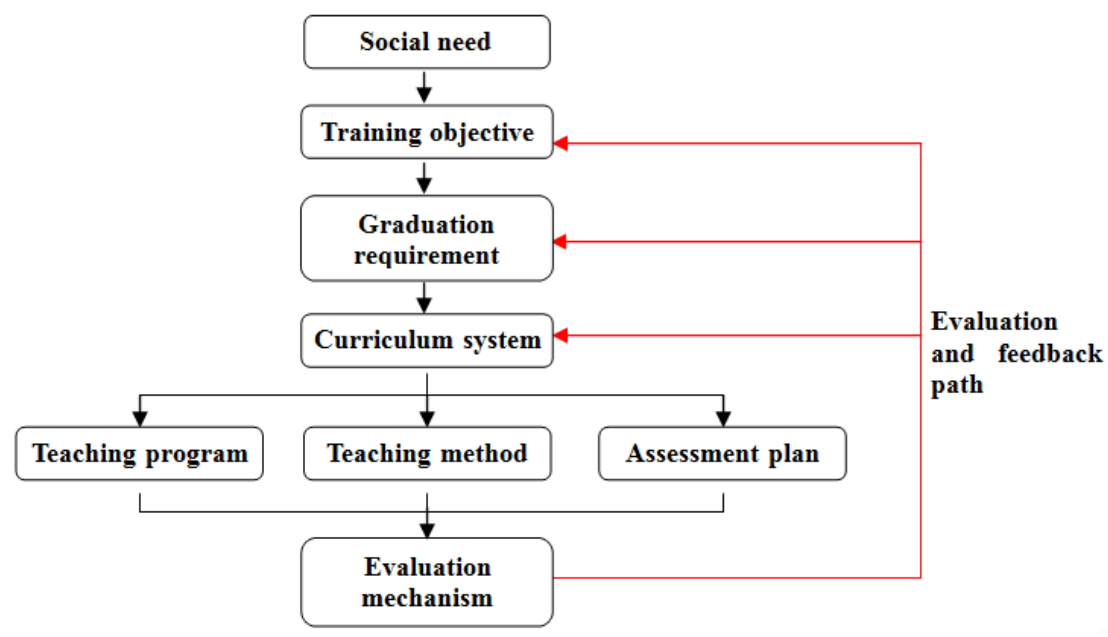

Fig. 1. Teaching mode of the OBE concept

The graduation requirement items supported by the blasting engineering curriculum and concrete index points are shown in Table 1. The curriculum objectives designed on this basis are as follows:

- O1: Be able to comprehend and master all blasting engineering techniques through bibliographic retrieval and cultivate one's retrieval ability

- O2: Be capable of task analysis and take full advantage of various useful resources to cultivate one's problem analysis ability

- O3: Be able to select an appropriate design scheme by combing reliability and realizability, among others, and cultivate one's scheme design ability

- O4: Be able to effectively evaluate the differences among different schemes and cultivate one's ability to analyze design schemes

- O5: Be able to coordinate work in groups, reasonably decompose work tasks, cooperate, and cultivate one's cooperative ability

- O6: Be able to gradually cultivate one's oral expression ability through communication in the practice process and make comprehensive, correct, and logically clear expressions for the problems to be addressed.

The corresponding relations of the above curriculum objectives to the index points of graduation requirements are shown in Table 1. 
Table 1. Results of the two tests in Wechat Group and Control Group

\begin{tabular}{|l|l|c|}
\hline \multicolumn{1}{|c|}{ Graduation requirement } & \multicolumn{1}{|c|}{ Index point } & $\begin{array}{l}\text { Curriculum } \\
\text { objective }\end{array}$ \\
\hline $\begin{array}{l}\text { (II) Problem analysis: Be able to analyze complicat- } \\
\text { ed engineering problems in the mining engineering } \\
\text { field through literature review guided by basic } \\
\text { theories of natural science, such as mathematics and } \\
\text { mechanics, and acquire effective conclusions. }\end{array}$ & $\begin{array}{l}\text { 2.2: Be able to recognize the diversity } \\
\text { of solutions and seek multiple solu- } \\
\text { tions to complicated engineering } \\
\text { problems. }\end{array}$ & O1, O2 \\
\hline $\begin{array}{l}\text { (III) Design and development of solutions: Be able } \\
\text { to design solutions to complicated mining engineer- } \\
\text { ing problems and embody the consciousness of } \\
\text { innovation in design links in consideration of } \\
\text { society, health, safety, law, culture, and environ- } \\
\text { ment. }\end{array}$ & $\begin{array}{l}\text { 3.3: Master the design methods in the } \\
\text { mining engineering field and embody } \\
\text { the consciousness of innovation in } \\
\text { design links in consideration of safety } \\
\text { and environment, among others. }\end{array}$ & O3, O4 \\
\hline $\begin{array}{l}\text { (VI) Engineering and society: Be able to analyze } \\
\text { and evaluate the influences of design scheme on the } \\
\text { economy, environment, law, safety, health, and } \\
\text { ethics based on related engineering background } \\
\text { knowledge and understand the bounden duties; }\end{array}$ & $\begin{array}{l}\text { 6.1: Be able to evaluate the influences } \\
\text { of solutions to complicated problems } \\
\text { in the mining engineering field on } \\
\text { society, safety, and environment, } \\
\text { among others. }\end{array}$ & O3, O4 \\
\hline $\begin{array}{l}\text { (X) Communication: Be able to effectively com- } \\
\text { municate and exchange overcomplicated engineer- } \\
\text { ing problems with peers in the industry and the } \\
\text { social public by writing reports and manuscripts, } \\
\text { making statements and speeches, and clearly ex- } \\
\text { pressing or responding to commands. Have a cer- } \\
\text { tain international vision and be able to communicate } \\
\text { under a cross-cultural background. }\end{array}$ & $\begin{array}{l}\text { 10.1: Be able to clearly express or } \\
\text { respond to commands for complicated } \\
\text { engineering problems and their solu- } \\
\text { tions via oral statements, reports, or } \\
\text { manuscripts. Be able to effectively } \\
\text { communicate and exchange with } \\
\text { peers in the industry by using modern } \\
\text { information technology. }\end{array}$ & O5, O6 \\
\hline
\end{tabular}

\subsection{Project topic selection}

According to the curriculum objectives of blasting engineering, the abilities of students that need to be trained and cultivated in the teaching process are very similar to the objectives that should be reached by the project-driven teaching method in engineering education [13]. Therefore, the OBE concept was combined with a projectdriven teaching method in the teaching mode design for the blasting engineering curriculum.

On the precondition that the curriculum training objectives can be reached following the blasting engineering teaching program, common blasting projects were selected to improve the practicality and pertinence of the teaching projects. For the teaching contents of blasting engineering, six special topics were selected, namely, pre-split blasting and polished surface blasting scheme design, deep hole bench blasting scheme design for open-pit mines, roadway excavation blasting scheme design for underground mines, stope blasting scheme design for underground mines, demolition blasting scheme design, and blasting vibration monitoring scheme design.

\subsection{Project implementation}

The concrete project implementation was divided into four phases, namely, project investigation and analysis, project parameter design, project report evaluation, and project display and feedback, as shown in Fig. 2. 


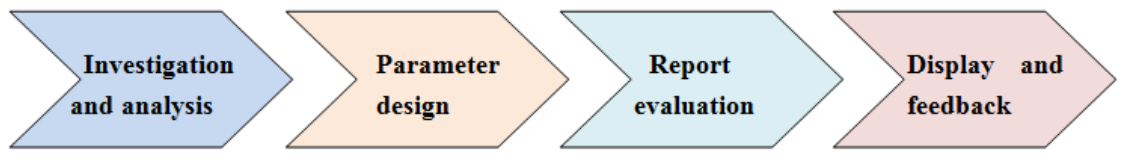

Fig. 2. Specific implementation steps of the project-driven teaching method

In the first step (investigation and analysis), the teacher briefly introduced the basic design principles of the special project in the classroom. Based on these principles, the students were grouped (each group having four students) to conduct investigation and analysis using textbooks or other reference materials. Based on the investigation results and the project background information, each student proposed his/her design scheme, and each scheme was evaluated through a group discussion. A scientific and reasonable implementation plan was then formulated.

In the second step (parameter design), the members of each group were assigned work tasks. During the implementation process, the teacher actively assessed the progress of the design and the related examination work in each group. The teacher also encouraged the students to answer the questions in the design by conducting literature reviews and group discussions.

In the third step (report evaluation), each group performed self-inspection and evaluated the related design results to perfect and submit their design scheme report in the form of a project proposal that contains the engineering background information of the project, the project investigation and analysis, the project scheme design, the project implementation steps, and other details. The corresponding safety evaluation was also conducted.

In the fourth step (display and feedback), each group carefully prepared a PowerPoint presentation, concisely explained the related contents in their project proposal, and answered the questions of their teacher and classmates. Afterward, the teacher gave a summative evaluation of the advantages and disadvantages of the projects to guide each group in further perfecting or upgrading their software platform.

\subsection{Project evaluation}

The curriculum teaching evaluation and feedback based on OBE and the continuous improvement of the teaching method play indispensable roles in improving learning quality and serve as an effective mechanism that ensures that the students can fulfil the undergraduate program training objectives in engineering education [9]. Therefore, related evaluation contents were formulated according to the evaluation mechanism of curriculum learning quality as shown in Table 2. After the project implementation, the teacher evaluated the students and groups separately based on certain evaluation indicators and then checked their project results. The teacher also summarized and reviewed the theoretical knowledge of the whole project and then evaluated the performance of students in the project implementation. The teacher also addressed the weaknesses of the students in training continuously and pertinently according to the evaluation mechanism. 
Paper-Experiences from a New Project-Driven and Outcome-Based Educational Concept in a Blasting...

Table 2. Evaluation indicators and weights of the learning quality of students

\begin{tabular}{|c|c|c|c|}
\hline \multicolumn{2}{|c|}{ Project phase } & \multicolumn{2}{|c|}{ Evaluation index } \\
\hline Content & Weight & Content & Weight \\
\hline \multirow{3}{*}{ Investigation and analysis } & \multirow{3}{*}{0.2} & Sufficient investigation & 0.10 \\
\hline & & Reasonable analysis & 0.05 \\
\hline & & Correct principle & 0.05 \\
\hline \multirow{4}{*}{ Parameter design } & \multirow{4}{*}{0.4} & Accurate calculation & 0.15 \\
\hline & & Communication and cooperation & 0.15 \\
\hline & & Reasonable progress & 0.05 \\
\hline & & Check and correction & 0.05 \\
\hline \multirow{3}{*}{ Report evaluation } & \multirow{3}{*}{0.2} & Reasonable evaluation & 0.10 \\
\hline & & Handsome chart & 0.05 \\
\hline & & Format planning & 0.05 \\
\hline \multirow{3}{*}{ Display and feedback } & \multirow{3}{*}{0.2} & Intact content & 0.10 \\
\hline & & Clear logic & 0.05 \\
\hline & & Fluent response & 0.05 \\
\hline
\end{tabular}

\section{Teaching Implementation and Effect}

\subsection{Teaching case}

A case study of a deep hole bench blasting scheme design for an open-pit mine was explored by using the project-driven teaching method. The project contents were decomposed according to the curriculum training objectives and knowledge points in each unit as shown in Fig. 3. 


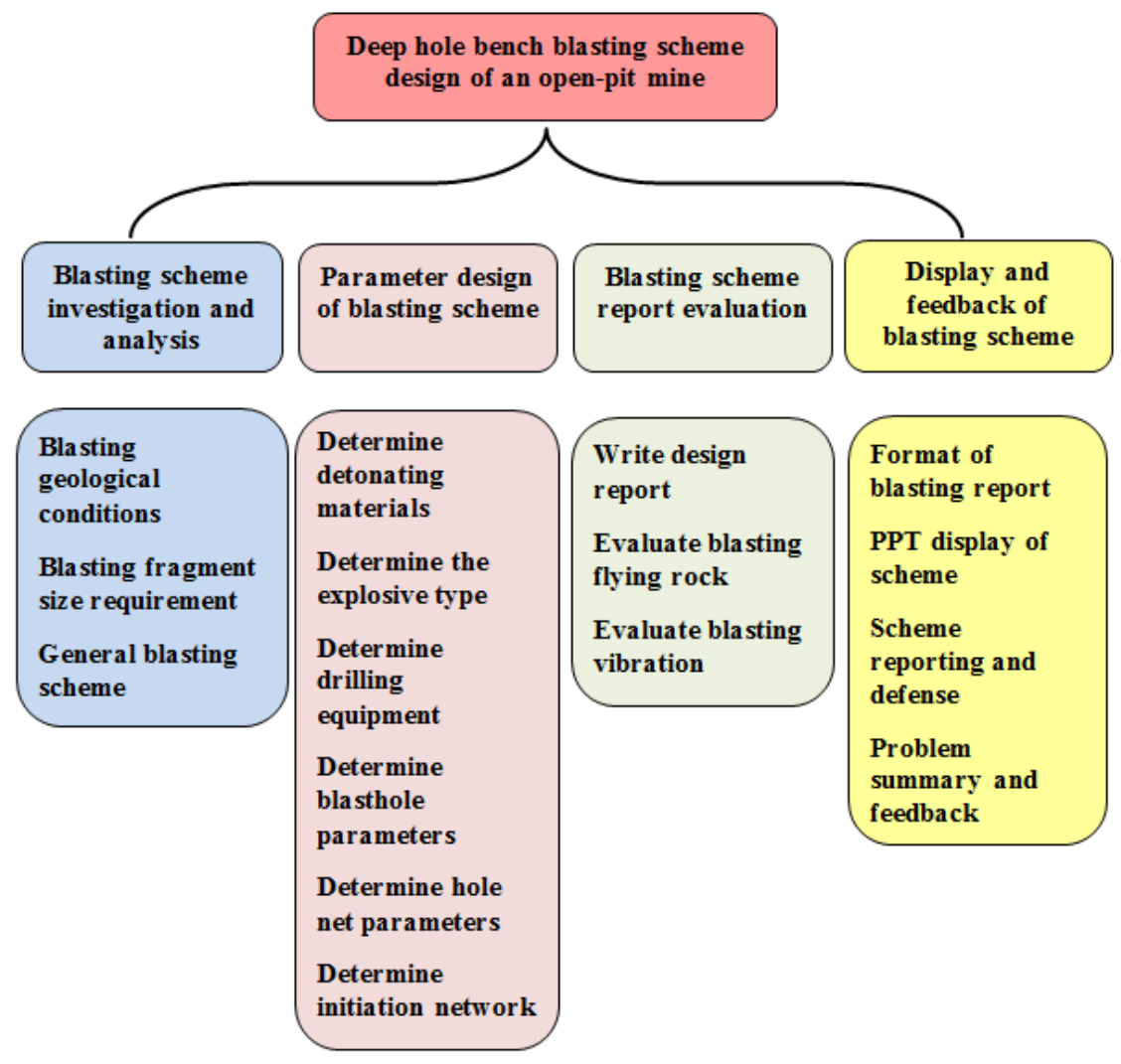

Fig. 3. Content and task decomposition of the deep hole bench blasting project of an open-pit mine

\subsection{Investigation and analysis of the blasting scheme}

The teacher briefly introduces the basic design contents of the deep hole bench blasting scheme for an open-pit mine in the classroom and demonstrates the 1185 horizontal bench blasting design of the Heidaigou open-pit mine [19]. After the discussion, the students gain a comprehensive cognition of the blasting scheme, analyze the blasting task requirements, and select the blasting scheme according to the geological conditions and blasting environmental requirements. The influences of the geological conditions on the blasting effect are analyzed by combing textbook theories, including rock grading, rock mass structure, topography, and underground water [20]. The detonation method is then determined based on the blasting environmental requirements, such as the electromagnetic environment and conditions of protected buildings within the blasting scope. The number of blast holes is calculated based on the requirements for the blasting area, the selected detonation method, and the blasting fragment size. The overall scheme, including the depth of the blast hole, the form of the drill hole, the hole arrangement pattern, and the detonation method, is then 
confirmed. Afterward, the students are required to draw the bole hole layout plan as shown in Fig. 4. Through the project investigation and analysis, the students can learn to how to find related literature from various databases, master the basic literature analysis ability, present a preliminary literature review respective to the research topic, and clarify the advantages and disadvantages of related research.

According to the geological information given in the project, to improve the stability and quality of the surrounding rocks, a group of students adopted the blasting technique that integrates inter-row millisecond delay blasting and pre-split blasting.

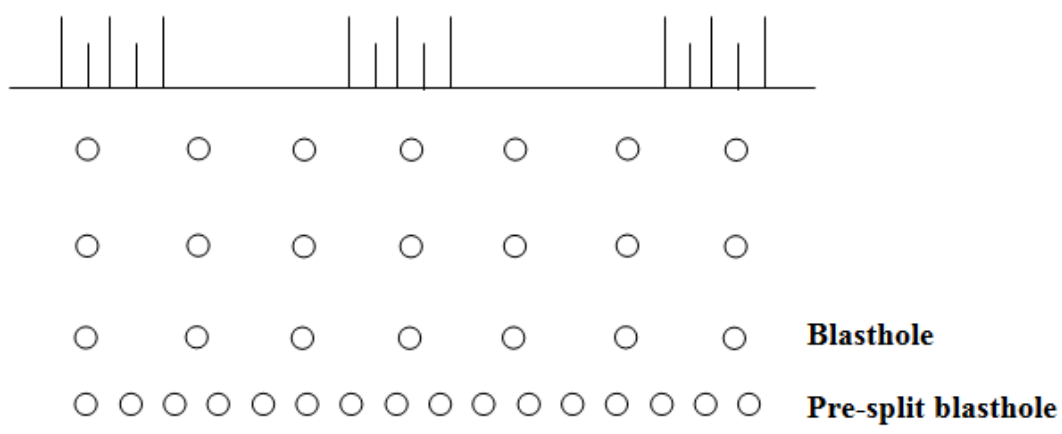

Fig. 4. Blast hole layout

\subsection{Parameter design of the blasting scheme}

The students are required to choose among explosives and detonating materials based on the blasting rock mass properties, groundwater level, blast hole depth, blasting scope, and detonating method and then check the related parameters. Through a selection and evaluation of the blasting materials, the students could gain a deep understanding of the basic properties and service conditions of industrial explosives and detonating materials, which would lay a solid foundation for their further study of detonating methods and detonating network designs. The non-electric detonation system was selected by the group. In this system, a shock tube was used as the detonating propagation element, a four-way connector was used as the connecting element, and a non-electric millisecond delay detonator was used as the detonating element.

The blasting parameter design was considered the key content in this project, and the following contents were mainly designed: (1) Determine the drilling equipment, that is, confirm the related drilling equipment and conduct calculate the safe edge distance of bench holes according to the blast hole depth, drilling form, and hole arrangement mode, among others; (2) design the blast hole parameters, such as the blast hole depth, toe burden, and blockage length; (3) design the hole net parameters, including the blast hole and row spacing's, blast hole density coefficient, charging structure, unit consumption, single-hole charge, and total charge; and (4) design the detonating network, calculate the millisecond delay (including the spatial and interrow time difference), confirm the burning front and detonating order, and select the 
specifications, models, and quantities of the corresponding detonating materials. After completing the parameter design for the detonating scheme, the students were asked to draw blast hole charging structure and detonating network charts.

The air gap charging structure was adopted by the group, and the air gap cartridges inside the blast hole were connected by a detonating cord as shown in Fig. 5. The outer hole millisecond delay detonating network was used, all blast holes in the same row were connected in series, and all rows were connected in parallel. The back row was connected by an MS9 shock-tube delay detonator, whereas the other rows were connected by an MS5 shock-tube delay detonator. Two principal cords were used to connect the closed ring network left and right, and a double-safety and multiloop detonating network was formed as shown in Fig. 6.

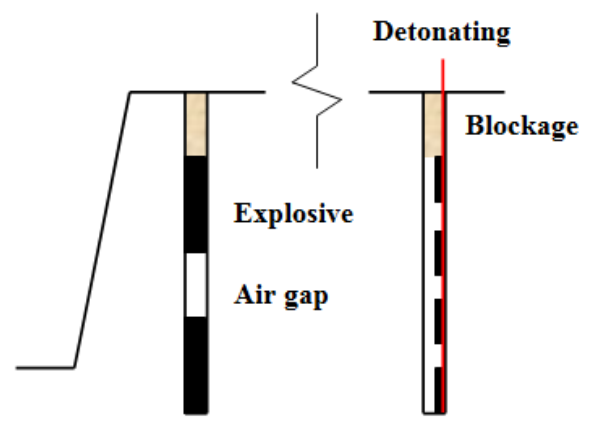

Fig. 5. Specific implementation steps of the project-driven teaching method

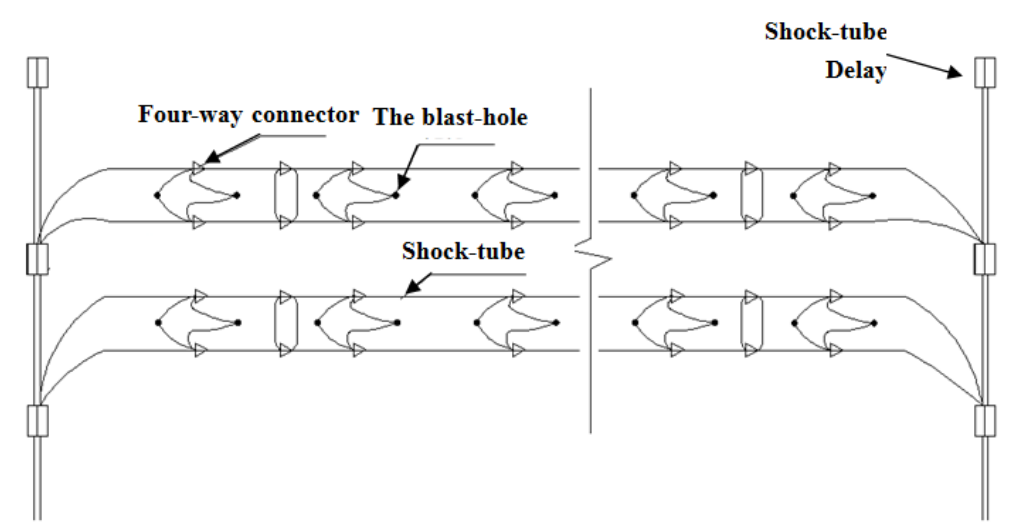

Fig. 6. Schematic diagram of the detonating network

\subsection{Evaluation of the blasting scheme report}

Blasting engineering involves high risk. Therefore, ensuring blasting safety is the basic requirement in blasting engineering. The causes for open-pit deep blasting hazards have been evaluated mainly from two aspects, namely, blasting flying rock and 
blasting vibration [21-22]. The flying distance of rocks has been calculated and taken as the main basis for demarcating the scope of blasting safety alert and is determined by combining the related stipulations specified in Safety Regulations for Blasting [23]. To avoid the destructive influence of blasting vibration on nearby factory buildings, the permissible maximum simultaneous blasting safety charge must be calculated according to the resistance to shock of the buildings and houses located closest to the detonating point, and the calculation result should be compared with the maximum simultaneous blasting charge in the blasting design to correct the design parameters. Based on a comprehensive analysis of the causes of blasting hazards, effective elimination or control measures for blasting hazards should be scientifically implemented to ensure the safety of personnel and building facilities and to facilitate the implementation of blasting work. The students in this group proposed related measures from three aspects, namely, shock absorption, flying rock prevention technology, and prevention of extraneous electricity. Afterward, they organized the design process, concrete parameters, and drawings for the safety evaluation and wrote a design report.

Project report evaluation is a key step in the whole project-driven teaching mode and is considered an important phase in cultivating the engineering practical abilities of students [24]. After the teacher explained the practical blasting schemes, the students drew inferences through deep understanding and analysis and continuously improved their abilities in scheme design and risk evaluation through mutual learning and communication within the group. Similarly, the training in project scheme writing allowed the students to familiarize themselves with the design flow and compilation requirements for the blasting scheme, helped them improve the format of their report, and effectively improved their abilities in using Office software.

\subsection{Blasting scheme display and feedback}

After the project was completed, the students organized the related design process and drawings, formulated the design instructions, and disseminated the project results in the form of a PowerPoint presentation. In each step of the project process, the teacher carefully recorded the learning process and results of the students based on the evaluation indicators and weights for their learning quality as listed in Table 1 and then obtained the complete evaluation results. The teacher timely summarized the problems appearing in the project implementation process and proposed the necessary measures to facilitate continuous improvement.

The project-driven teaching was carried out for the abovementioned six special subjects during the spring semester of 2020, and the performances of the students were evaluated based on the indicators listed on Table 1. The average scores of the groups were calculated according to the practical teaching sessions and are shown in Fig. 7. The average scores increased for each evaluation content, thereby highlighting a continuous improvement in the comprehensive abilities of the students. However, randomness was evident in their project defense performance. As for the teaching evaluation feedback, the improvement measure was to carry out a pre-defense within the group followed by project reporting and defense after a full discussion, which can 
improve the communication and reporting abilities of the students while strengthening their problem summarization and analysis abilities.

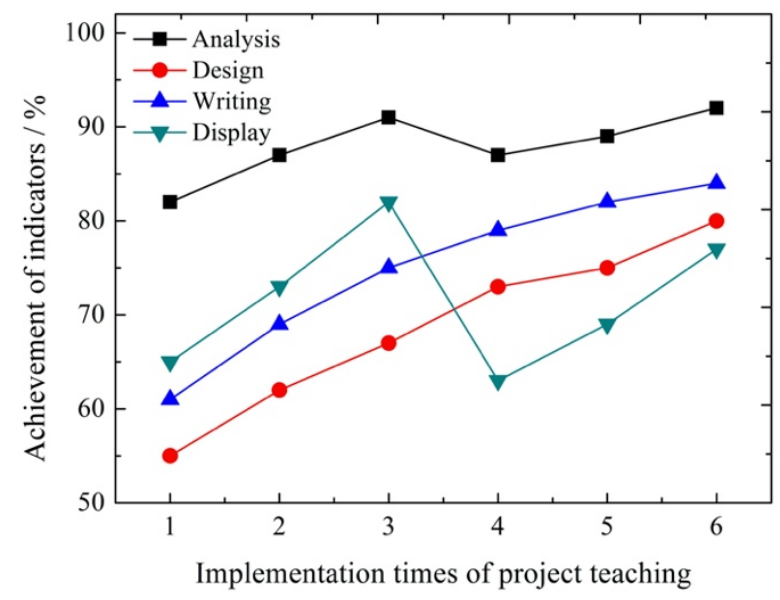

Fig. 7. Achievement of indicators in the learning quality evaluation of students

\subsection{Effect of continuous improvement in teaching}

Given that the project-driven teaching method was introduced into the blasting engineering curriculum teaching process in 2017, the weaknesses in the ability training of the students fed back by the abovementioned evaluation mechanism and the pertinent continuous improvement results in the subsequent teaching are shown in Table 3. The implementation of project teaching improved the participation, learning interest, and initiative of the students. Both the project-driven teaching and autonomous learning of this curriculum were accepted by the students, the teaching effect was apparently enhanced, the attendance rate of the students increased from $75 \%$ to $90 \%$, and the $\mathrm{B}$ grade rate increased from $50 \%$ to approximately $75 \%$. The four-year teaching practice shows that the project-driven teaching method based on OBE can steadily improve the comprehensive engineering practical abilities of the students. 
Table 3. Feedback of the evaluation mechanism and improvements in the teaching method over the past four years

\begin{tabular}{|c|l|l|}
\hline Year & \multicolumn{1}{|c|}{ Feedback information } & \multicolumn{1}{|c|}{ Improvement measure } \\
\hline 2017 & $\begin{array}{l}\text { The teacher explained the whole process yet neglected } \\
\text { the initiatives of the students. Therefore, the students } \\
\text { were uninterested in learning. }\end{array}$ & $\begin{array}{l}\text { The project-driven teaching model based } \\
\text { on the OBE concept was adopted. }\end{array}$ \\
\hline 2018 & $\begin{array}{l}\text { No evaluation was performed during the scheme } \\
\text { selection phase, and the students showed no progress } \\
\text { in their scheme analysis ability. }\end{array}$ & $\begin{array}{l}\text { Theories and methods for comparative } \\
\text { scheme analysis were introduced. }\end{array}$ \\
\hline 2020 & $\begin{array}{l}\text { After the scheme reporting, no summary was present- } \\
\text { ed. Therefore, the students had insufficient recognition } \\
\text { of their weaknesses. }\end{array}$ & $\begin{array}{l}\text { The teacher summarized and evaluated the } \\
\text { advantages and disadvantages of the } \\
\text { schemes and pointed out further improve- } \\
\text { ment directions. }\end{array}$ \\
\hline ability of the students was not improved. & $\begin{array}{l}\text { Pre-defense within the group increased the } \\
\text { degree of participation of the students in } \\
\text { the reporting. }\end{array}$ \\
\hline
\end{tabular}

\section{Conclusion}

Under the guidance of the OBE concept certified by the engineering education specialty, a project-driven teaching reform was carried out for the blasting engineering curriculum. Specifically, the textbook-centered mode was transformed into the project-centered mode, the teacher-centered model was transformed into the studentcentered model, and the classroom-centered mode was transformed into the engineering practice-centered mode. This reform helped the students enjoy the comprehensive engineering training and cultivated their quality, thus providing powerful support for the index points requiring decomposition for meeting the graduation requirements. The following conclusions are drawn:

1. After implementing the project-driven teaching method, the degree of participation of the students was obviously improved, and both of their learning interests and initiatives were strengthened. Both project-driven teaching and autonomous learning in this curriculum were accepted by the students, and the teaching effect was obviously improved.

2. The students mastered the blasting engineering knowledge points. By considering the problems in the field, the ability of the students in solving complicated engineering problems was strengthened, thereby fulfilling the teaching objectives and requirements specified in the teaching program.

3. The reform improved the bibliographic retrieval, independent thinking, team communication, cooperation, scheme writing, and oral expression abilities of the teachers, thereby laying a solid foundation for strengthening their overall quality.

The project-driven teaching method was explored in this study to address the problems in traditional classroom teaching and to improve the teaching effect. However, blasting engineering is a professional course with very strong operability. Therefore, the students are required to experience the blasting process in person. Given the high 
risk involved in engineering blasting, a complete engineering project implementation becomes difficult to realize in the teaching process. A virtual experimental environment can be established in the future teaching process via virtual simulation, multimedia, man-computer interaction, database, and network communication. Students can carry out blasting engineering projects in such virtual environment and improve their intuitive recognition of blasting engineering.

\section{Acknowledgement}

This work was supported in part by the Provincial Level Quality Engineering Project of Anhui Higher Education (2018jyxm1104, 2019jyxm1221, 2020xsxxkc153), Excellent Talent Training Project of Anhui Higher Education (2018zygc006) and Demonstration Project of Basic Teaching and Research Section of Anhui (2018jyssf014).

\section{$7 \quad$ References}

[1] Wang, X., Chen, C. (2012). Analysis on teaching reform of "Blasting Engineering" course for mining major, Journal of Hebei United University (Social Science Edition), 12(4), 8090.

[2] Zhu, D., Li, Y. (2011). Discussion on teaching methods and teaching effectiveness of engineering blasting course, Journal of Sichuan College of Education, 27(05), 122-124.

[3] Li, Z., Zhu, H., Liu, Z., Xia, Y. (2014). Guiding the reform of higher engineering education with result-oriented educational ideas, Research in Higher Education of Engineering, (02), 29-34, 70.

[4] Spady, W. G. (1994). Choosing outcomes of significance, Educational Leadership, 51(6), $18-22$.

[5] Harden, R.M. (2007). Outcome-Based education: the future is today, Medical Teacher, 29(7), 625-629. https://doi.org/10.1080/01421590701729930

[6] Kampouropoulou, Maria. (2015). The use of project method in teaching arts-an interdisciplinary the use of project method in teaching arts, an interdisciplinary approach in high school, Review of European Studies, 7(11), 159-165. https://doi.org/10.5539/res.v7n11p $\underline{159}$

[7] Ma, K., Teng, H., Du, L., Zhang, K. (2014). Project-driven learning-by-doing method for teaching software engineering using virtualization technology. International Journal of Emerging Technologies in Learning, 9(9), 26-31. https://doi.org/10.3991/ijet.v9i9.4006

[8] Liu, Q., Zhang, W., Wu, C. (2019). Research on blasting engineering curriculum reconfiguration, Journal of Longyan University, 37(02), 102-106.

[9] Zhang, F., Yang, X., Han, Y., Yang, M., Pan, R. (2020). Construction of experimental teaching platform for blasting safety during tunnelling based on virtual simulation, Experimental Technology and Management, 37(06), 151-156.

[10] Zhang, H. (2017). Application of flipped classroom in experimental teaching on Performance Test of Blasting Materials, Journal of Suzhou Education Institute, 20(06), 148-150.

[11] Zhylkybay, G., Magzhan, S., Suinzhanova, Z., Balaubekov, M., Adiyeva, P. (2014). The Effectiveness of Using the Project Method in the Teaching Process, Procedia - Social and Behavioral Sciences, 143, 621-624. https://doi.org/10.1016/j.sbspro.2014.07.448 
[12] Agudamu, H.T. (2020). Research on the teaching of undergraduate graduation project based on the cultivation of practical innovation ability, International Journal of Education and Economics, 3(2), 35-37.

[13] Qian, C.Y. (2015). Project teaching: an effective way to cultivate students' practical abilities, Research in Higher Education of Engineering, (02), 187-192.

[14] Su, P., Li, M. (2018). The construction on curriculum and teaching in general education in Tsinghua case: an approach of outcome-based education, Research in Higher Education of Engineering, (02), 129-135.

[15] Liu, Q. (2018). Remodeling of "software engineering" course based on OBE concept, China University Teaching, (10), 25-31.

[16] Du, X., Zhang, K. (2020). Reform of digital experimental teaching based on OBE concept, Experimental Technology and Management, 37(01), 181-186.

[17] Mohammad, S., Siang, T. C., Osman, S., Jamaluddin, N. Y., Huei, L. Y. (2019). A proposed heutagogy framework for structural steel design in civil engineering curriculum. International Journal of Emerging Technologies in Learning, 14(24), 96-105. https://doi.org/ 10.3991/ijet.v14i24.12091

[18] Zhang, Q., Chen, Y. (2018). Construction of multi-dimensional and laddered practical teaching system based on OBE, Research and Exploration in Laboratory, 37(03), 206-209, 225.

[19] Meng, H., Li, J., Gong, Y. (2013). Blasting design of $1185 \mathrm{~m}$ level bench of Heidaigou open-pit coal mine, Blasting, 30(02), 104-105, 114.

[20] Yin, Z.Q., Hu, Z.X., Wei, Z.D., Zhao, G.M., Ma, H.F., Zhang, Z., Feng, R.M. (2018). Assessment of Blasting-Induced Ground Vibration in an Open-Pit Mine under Different Rock Properties, Advances in Civil Engineering, 2018, 1-10. https://doi.org/10.1155/2018/ $\underline{4603687}$

[21] Simangunsong, G. M., Wahyudi, S. (2015). Effect of bedding plane on prediction blastinduced ground vibration in open pit coal mines, International Journal of Rock Mechanics and Mining Sciences, 79, 1-8. https://doi.org/10.1016/j.ijrmms.2015.08.004

[22] Armaghani, D.J., Hajihassani, M., Mohamad, E.T., Marto, A., Noorani, S. A. (2014). Blasting-induced flyrock and ground vibration prediction through an expert artificial neural network based on particle swarm optimization, Arabian Journal of Geosciences, 7(12), 5383-5396. https://doi.org/10.1007/s12517-013-1174-0

[23] Standards of the People's Republic of China. (2014). Safety Regulations for Blasting (GB6722-2014), China Standard Press.

[24] APARajak, A., Shrivastava, A.K., Tripathi, A.K. (2019). An approach to evaluate program outcomes and program educational objectives through direct and indirect assessment tools, International Journal of Emerging Technologies in Learning, 14(23), 85-97. https://doi.org/10.3991/ijet.v14i23.11018

\section{Authors}

Zhiqiang Yin is a professor in the School of Mining, Anhui University of Science and Technology, Huainan, 232001, China (zhqyin@aust.edu.cn)

Zenghui Liu is a professor in the School of Mining, Anhui University of Science and Technology, Huainan 232001, China (954371093@qq.com) 
Zhixiong Zhang (corresponding author) is a senior engineer in the College of Civil Engineering and Architecture, Beibu Gulf University, Qinzhou 535011, China (zzxiong@bbgu.edu.cn)

Jucai Chang is a professor in the Key Laboratory of Safety and High-efficiency Coal Mining, Huainan 232001, China (cjcminecoal@163.com)

Xuelong $\mathrm{Hu}$ is lecturer in the Key Laboratory of Safety and High-efficiency Coal Mining, Huainan 232001, China (xuelonghu@aust.edu.cn)

Article submitted 2021-01-21. Resubmitted 2021-03-01. Final acceptance 2021-03-05. Final version published as submitted by the authors. 